\title{
Quality of life after ischaemic stroke-accent on patients with thrombolytic therapy
}

\author{
Mihael Emilov Tsalta-Mladenov ${ }^{1,2^{*}}$ (1) and Silva Peteva Andonova ${ }^{1,2}$
}

\begin{abstract}
Background: Intravenous thrombolysis is a widely approved treatment method for acute ischemic stroke (AIS). Nevertheless, there is a growing interest in its impact on functional outcomes and Health-related Quality of life (HR-QoL). We aimed to evaluate and compare the HR-QoL in patients receiving intravenous thrombolysis (IVT) and in those without thrombolytic therapy during the first 3-month post-stroke in a defined Bulgarian population.

Results: Patients treated with IVT have simillar functional outcomes and HR-QoL on the third month as the group with conservative treatment, besides their higher NIHSS on admission. Patients with IVT had better self-assessed recovery after the AIS. The higher NIHSS and mRS scores and the lower HR-QoL on discharge are reliable predictors for a poor functional outcome on the third month. A door-to-needle of $60 \mathrm{~min}$ or less, and the absence of pathological neuroimaging findings 24-h post IVT predict more beneficial HR-QoL outcome.

Conclusion: There were no significant differences in HR-QoL and functional outcomes between the groups. Nevertheless, IVT is a treatment option with great importance for improving the clinical outcomes after ischemic stroke, which should be performed in well selected patients.
\end{abstract}

Keywords: Health-Related Quality of life, Quality of life, Intravenous Thrombolysis, Ischemic Stroke, Stroke Impact Scale

\section{Background}

Stroke is one of the leading causes of death and chronic disability worldwide [1]. The incidence of stroke in Bulgaria is the highest with four times higher death rates among the other European countries. A large variety of clinical and functional outcomes can be observed in stroke patients, ranging from full recovery to severe functional dependence or even death [2].

Thrombolytic therapy with intravenous tissue plasminogen activator (IV tPA) administered within $4.5 \mathrm{~h}$ of first symptom onset is nowadays widely used and highly effective treatment for ischemic stroke patients, which significantly reduces the neurological deficit [3]. Despite the improvement in the acute treatment, a lot of patients

\footnotetext{
*Correspondence: MihaelTsalta@gmail.com

1 Department of Neurology and Neuroscience, Faculty of Medicine,

Medical University "Prof. Paraskev Stoyanov", Varna, Bulgaria

Full list of author information is available at the end of the article
}

are still deemed to live with multiple handicaps and longterm impairments [4]. During the last decades, Healthrelated Quality of life (HR-QoL) after acute ischemic stroke (AIS) is a growing area of interest [5]. Post-stroke patients often have a multifactorial deterioration in functioning, requiring long-term care [2]. Long-term disability is widespread among stroke survivors, causing problems in different aspects of their lives, such as activities of daily living (ADL) and social participation [6].

Little is known about the long-term effects after ischemic stroke in the Bulgarian population especially for patients treated with intravenous thrombolysis (IVT). It is essential to know the differences in outcomes and predictive factors for functional outcomes in patients who received thrombolysis and in those who did not receive this kind of treatment.

The present study aimed to measure and compare the HR-QoL in patients receiving intravenous thrombolysis and in those without thrombolytic therapy during the 
first 3-months post-stroke in a defined Bulgarian population. In addition, we evaluated the impact of various clinical features on the total HR-QoL and investigated their predictive value on the functional outcome in patients treated with IVT in the third-month post-stroke.

\section{Methods}

\section{Study design and participants}

We conducted a prospective, hospital-based study from July 2019 to June 2020, in Second Clinic of Neurology with ICU and stroke unit at the University Hospital "St. Marina", Varna, Bulgaria.

Consecutive patients with first-ever and recurrent acute ischemic stroke (AIS) were included in the present study. A total of 150 patients we recruited at baseline -50 patients with intravenous thrombolysis and 100-with non-thrombolytic treatment. The non-thrombolized patients (NTP) were patients admitted after the therapeutic window for intravenous thrombolysis (IVT) or had contraindications according to the European Stroke Organisation (ESO) guidelines on intravenous thrombolysis for acute ischaemic stroke [7]. We used the American Heart Association/American Stroke Association (AHA/ ASA) definition of stroke [8]. Ethical permission was obtained from the ethics committee of the Medical University Varna. All participants provided signed informed consent.

We accepted the following inclusion criteria: age of 18 years or more; acute onset of neurological symptoms lasting more than $24 \mathrm{~h}$; conducted neuroimaging examination of the head-computed tomography (CT) or magnetic resonance imaging (MRI); and signed informed consent.

Exclusion criteria were: age under 18 years; lack of neurological symptoms; patients with a transient ischemic attack (TIA); refusal to sign an informed consent.

\section{Clinical evaluation and measures}

All participants were interviewed by a neurologist in an as similar as possible manner to get accurate demographic data, social history, and information for comorbidities and stroke risk factors. Medical records were checked, and relatives and caregivers were also interviewed. All participants underwent a detailed medical examination with thorough neurological status, blood tests, neuroimaging-computed tomography $(\mathrm{CT})$ on admission.

All participants were classified according to the etiopathogenesis of the cerebral infarction by the Trial of ORG 10,172 in Acute Stroke Treatment (TOAST) [9]. This classification is differentiating ischemic stroke into five subtypes: large-artery atherosclerosis, cardio-embolism, small-vessel occlusion (lacunar), a stroke of other determined etiology-arterial dissection, vasculitis, hematological diseases, and others, and stroke of undetermined etiology. In addition, we collected data regarding the involved vascular system-anterior or posterior circulation. In all cases of carotid stroke, we additionally recorded which hemisphere was affected.

Stroke severity was measured on admission and discharge from the clinic with the National Institutes of Health Stroke Scale (NIHSS) [10]. Disability and functional independence of patients were measured with the modified Rankin Scale (mRS) [11]. Stroke survivors were categorized as functionally independent (mRS 0-2 points) and functionally dependent (mRS $3-5$ points).

The Stroke Impact Scale Version 3.0 (SIS 3.0) [12] was applied to evaluate the Health-Related Quality of Life (HR-QoL) on discharge and at two follow-ups-at the first and the third-month post-stroke. In this study, we used the mean domain-specific and the mean total SIS 3.0 score as a measure of the HR-QoL.

\section{Statistical analysis}

The data analysis was carried out using gold standard methods widely reported in the HR-QoL literature [13]. We analyzed the HR-QoL data obtained at all three-timepoints. The items were recalibrated so that a high score always indicate better HR-QOL. The domain results are later rescaled by the following equation: domain score $=[($ Mean item score -1$) / 5-1] \times 100$. The calculated final scores have a standard range from 0 to 100 , where a score of 100 denotes the best health [14]. The overall HRQOL score was generated by finding the arithmetic mean of all the domain scores.

The statistical analysis included descriptive and inferential statistics. A comparison of the participants' responses was made using ANOVA and correlation statistics. We used frequencies and medians with 95\% confidence intervals (CI). General linear modelling was used to measure the changes in all SIS 3.0 domains over time. A regression model was used to establish the extent of the influence of different clinical features on the total SIS 3.0 scores. Receiver operator characteristic (ROC) curve was used to plot baseline stroke characteristics and indicators in relation to the 90-day unfavourable outcomefunctional dependency. We quantified the accuracy and the independent effect of these factors by calculating the area under the curves (AUC). The discrimination of each factor was evaluated in accordance with the suggestions by Hosmer and Lemeshow [15]: excellent (AUC $\geq 0.90$ ), good (AUC $\geq 0.80$ and $<0.90$ ), fair (AUC $\geq 0.70$ and 0.80 ), and poor ( $\left.\mathrm{AUC}^{<} 0.70\right)$. Statistical significance was defined as a $P$ value (alpha) of 0.05 or less.

Data were analyzed using the software programs SPSS, version 23.00 (IBM Statistics, USA) and GraphPad Prism, 
version 5.00 (GraphPad Software, San Diego California, USA).

\section{Results}

\section{Baseline characteristics}

A total of 150 patients were enrolled in this study-50 thrombolized patients (TP) and 100 non-thrombolized patients (NTP). Three patients-two TP and one NTP, were lost to follow-up between discharge and the firstmonth visit. A further four patients, all from the NTP group, were lost by the third-month post-stroke. Participants from both groups were age and sex-matched. The main baseline characteristics are presented in Table 1.

Various differences between the two groups have to be highlighted. First, most of the patients who received IVT had their first-ever stroke $(p=0.027)$, as there was predominantly anterior circulation stroke $(p=0.002)$. Secondly, patients from the TP group had significantly higher NIHSS score on admission-10.78 \pm 4.66 in comparison with the NTP group-6.59 $\pm 4.15(p<0.001)$. Subsequently, there was no significant inter-group difference in the NIHSS scores on discharge, which indicates a better recovery in the TP group. A higher prevalence of hypertension and atrial fibrillation was found in TP patients, while diabetes mellitus was more common in non-thrombolized patients.

\section{Main results}

The level of autonomy and HR-QoL from discharge to 3-month post-stroke improved in all SIS 3.0 domains for both groups. All domains in the TP group presented with a more remarkable improvement in the mean scores, especially for the first period between discharge and the first month. No significant inter-group differences were noted, except for the level of communication impairments on discharge, which were more severe at the NTP group. Another noteworthy difference was the level of self-assessed recovery after the acute ischemic stroke (AIS). In all three timepoints, patients with thrombolytic treatment reported significantly higher recovery poststroke. The level of dependency did improve over the first 3 months, while there were no differences in the comparison of the two groups.

Detailed information about the comparison of the HR-QoL and disability level in patients with thrombolysis and those with non-thrombolytic treatment are presented in Table 2.

Table 1 Patient characteristics at baseline

\begin{tabular}{|c|c|c|c|c|c|c|}
\hline \multirow[t]{2}{*}{ Factors } & & \multicolumn{2}{|c|}{$\begin{array}{l}\text { Thrombolized patients (TP) } \\
(n=50)\end{array}$} & \multicolumn{2}{|c|}{$\begin{array}{l}\text { Non-thrombolized patients (NTP) } \\
(n=100)\end{array}$} & \multirow[t]{2}{*}{$P$ value } \\
\hline & & $N$ & $\%$ & $N$ & $\%$ & \\
\hline \multirow[t]{2}{*}{ Age } & Mean (years) & $68.64 \pm 12.29$ & & $68.82 \pm 10.93$ & & 0.927 \\
\hline & $>65$ years & 31 & 62.0 & 65 & 65.0 & 0.720 \\
\hline \multirow[t]{2}{*}{ Sex } & Male & 32 & 64.0 & 58 & 58.0 & 0.483 \\
\hline & Female & 18 & 36.0 & 42 & 42.0 & \\
\hline \multirow[t]{2}{*}{ Ischemic stroke } & First-ever stroke & 44 & 88.0 & 72 & 72.0 & 0.027 \\
\hline & Recurrent stroke & 6 & 12.0 & 28 & 28.0 & \\
\hline \multirow[t]{4}{*}{ Localization } & Anterior circulation & 34 & 68.0 & 42 & 42.0 & 0.002 \\
\hline & - Left hemisphere & 19 & 38.0 & 28 & 28.0 & 0.216 \\
\hline & - Right hemisphere & 15 & 30.0 & 14 & 14.0 & 0.019 \\
\hline & Posterior circulation & 16 & 32.0 & 58 & 58.0 & 0.002 \\
\hline \multirow[t]{2}{*}{ Stroke severity } & Mean (NIHSS) on admission & $10.78 \pm 4.66$ & & $6.59 \pm 4.15$ & & $<0.001$ \\
\hline & Mean (NIHSS) on discharge & $5.78 \pm 4.52$ & & $4.53 \pm 3.56$ & & 0.067 \\
\hline Level of dependence & Mean (mRS) on discharge & $2.92 \pm 1.47$ & & $2.49 \pm 1.45$ & & 0.090 \\
\hline \multirow[t]{7}{*}{ Risk factors } & Hypertension & 48 & 96.0 & 100 & 100.0 & 0.044 \\
\hline & Atrial fibrillation & 23 & 46.0 & 25 & 25.0 & 0.009 \\
\hline & Myocardial infarction & 5 & 10.0 & 4 & 4.0 & 0.147 \\
\hline & Ischemic heart disease & 19 & 38.0 & 40 & 40.0 & 0.815 \\
\hline & Heart failure & 21 & 42.0 & 53 & 53.0 & 0.207 \\
\hline & Diabetes mellitus & 7 & 14.0 & 30 & 30.0 & 0.032 \\
\hline & Dyslipidemia & 34 & 68.0 & 78 & 78.0 & 0.187 \\
\hline
\end{tabular}

Bold values indicate $P$ value is significant (less than 0.05 )

NIHSS National Institutes of Health Stroke Scale, mRS modified Rankin Scale 


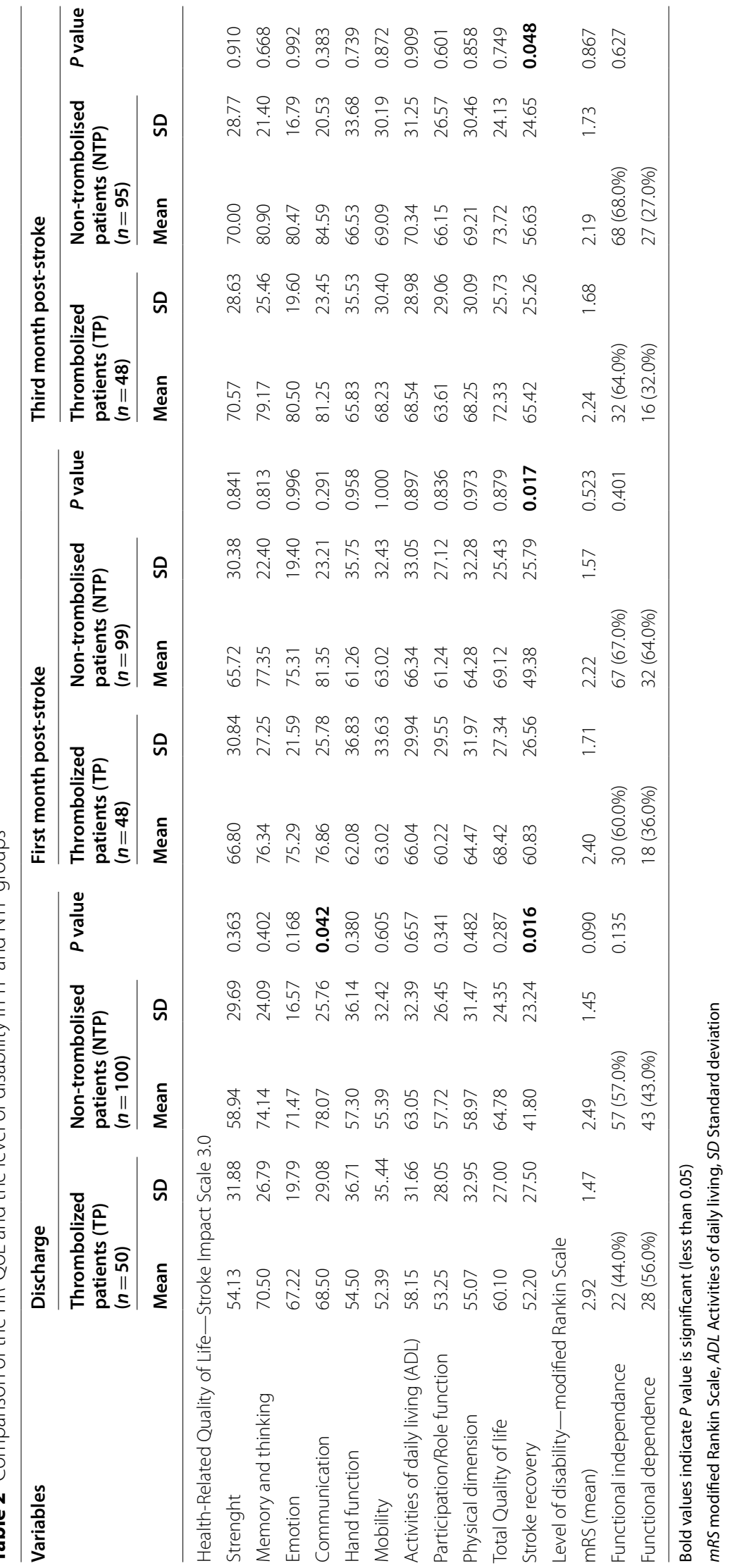


Accenting on the patients who received intravenous thrombolysis, we found a significant negative association between the patient's age and the HR-QoL on the third-month post-stroke. Being at the age of $\geq 65$ years is a predictor of more unsatisfactory outcome after ischemic stroke, as the mean HR-QoL is about 21.95 units lower than the younger patients $(p=0.003)$. Gender did not influence the outcome after intravenous thrombolysis.

All vascular risk factors were related to a different extent to a poor HR-QoL. Patients who undergo intravenous thrombolysis and have coronary artery disease (CAD), myocardial infarction (MI), and atrial fibrillation (AF) have significantly reduced HR-QoL in the third month.

A significant negative correlation was found between the mean total SIS 3.0 score and neurological deficit measured by NIHSS, whereas the higher NIHSS score at discharge was predictive for much worse outcomes. Patients who experienced a more severe stroke, with higher neurological deficits, reported poorer HR-QoL $(p<0.001)$.

The shorter door-to-needle (DTN) time, less than $60 \mathrm{~min}$, was a significant predictor for more beneficial HR-QoL outcomes $(p=0.009)$. Contrariwise, DTN of $120 \mathrm{~min}$ or more was significantly associated with worse outcomes in total HR-QoL with approximately - 39.63 units lower $(p=0.008)$. No changes in the computed tomography (CT) imaging $24 \mathrm{~h}$ after the thrombolysis has a positive correlation with better HR-QoL in the third month $(p=0.011)$.

Detailed information on the factors influencing the stroke survivors' HR-QoL during 3 months after thrombolysis is presented in Table 3.

Furthermore, we analyzed the receiver operating characteristic (ROC) curves to measure sensitivity to change at the HR-QoL in the third-month post-stroke. This approach allowed us to assess whether some clinical characteristics and instruments used on admission and discharge, such as the NIHSS, mRS, and the total HRQoL measured by the SIS 3.0, can be used to determine the functional outcome at the third month.

All the three instruments-NIHSS, mRS, and SIS 3.0, had good discriminating characteristics for assessment of worse prognosis. The NIHSS score on admission had good predictive value, while NIHSS, mRS, and HR-QoL measured by SIS 3.0 on discharged presented with excellent discrimination. All other factors presented with AUC $<0.70$ and, therefore, were rated with low discriminatory capacity.

Details about the area under the curve (AUC) and significance values for the ROC curves of the different variables are presented in Table 4 and Fig. 1.

\section{Discussion}

In the present study, we assessed the HR-QoL of ischemic stroke patients 3 months after intravenous thrombolysis compared to patients who had not undergone thrombolytic therapy. We additionally focused on thrombolized patients (TP) and investigated various factors influencing the HR-QoL and the functional outcome at the thirdmonth post-stroke.

Both groups showed no difference in age and gender distribution. The TP group experienced much severe stroke in comparison to the group with non-thrombolytic treatment (NTP). A possible reason for this might be that patients with more severe neurological deficits call for emergency medical care. Therefore, they reach much earlier to a hospital, and they do not miss the therapeutic window for IVT.

The risk profile of the participants revealed a higher prevalence of atrial fibrillation (AF), a history of myocardial infarction (MI), and coronary artery disease (CAD) in the group with thrombolytic treatment. There are divergent results in the literature regarding the risk profile of ischemic stroke $[16,17]$. However, the prevailing view is that patients who have either CAD or MI are at higher risk for acute ischemic stroke (AIS) [18]. There are multiple cardiac complications from MI, such as ventricular dyskinesia, aneurism, or ischemic cardiomyopathy, which can manifest later as a source of embolism and cause an acute ischemic stroke [19]. Atrial fibrillation was a more prevalent risk factor in the TP group and a predictor of worse clinical outcome regarding HR-QoL in the third month. Some studies are indicating that comorbidity of AF is associated with better outcomes following thrombolysis [20]. On the contrary, in recent years, there is a growing number of studies reporting poor clinical outcomes [21, 22]. A meta-analysis proved that thrombolized patients with acute ischemic stroke (AIS) and AF have higher mortality rates and symptomatic intracerebral hemorrhage (SICH) and subsequently reduced HRQoL and worse functional outcome compared to patients without AF [23]. In addition, those patients had other risk factors, such as dyslipidemia and diabetes mellitus, which formed a complicated vascular background in the TP group.

We proved that despite the conducted thrombolysis in the acute stage of ischemic stroke, patients have a similar self-assessment of their Quality of life. This fact was notable in all three-timepoints-discharge, first and third-month post-stroke, while the only exception was the better self-esteem for recovery after the stroke in all timepoints. One possible explanation could be the more rapid improvement of the neurological symptomatic after the recanalization procedure. On discharge, we found a higher mean mRS score, while more patients in the TP 
Table 3 Factors influencing the HR-QoL in thrombolized patients on the third-month post-stroke

\begin{tabular}{|c|c|c|c|c|c|c|c|}
\hline \multirow[t]{2}{*}{ Factors } & & \multirow[t]{2}{*}{ Adjusted $R$ square } & \multirow[t]{2}{*}{ Beta } & \multirow[t]{2}{*}{ Std. error } & \multirow[t]{2}{*}{$P$ value } & \multicolumn{2}{|c|}{$\begin{array}{l}\text { Confidence interval for Beta } \\
(95 \% \mathrm{Cl})\end{array}$} \\
\hline & & & & & & Lower bound & Upper bound \\
\hline \multirow[t]{2}{*}{ Age } & For each additional year & 0.246 & -1.05 & 0.26 & $<0.001$ & -1.57 & -0.53 \\
\hline & $>65$ years of age & 0.156 & -21.95 & 7.04 & 0.003 & -36.13 & -7.76 \\
\hline \multirow[t]{2}{*}{ Gender } & Male & -0.019 & -2.52 & 7.84 & 0.749 & -18.30 & 13.26 \\
\hline & Female & -0.019 & 2.52 & 7.84 & 0.749 & -13.26 & 18.30 \\
\hline \multirow[t]{8}{*}{ Risk factors } & Hypertension & 0.024 & -26.89 & 18.36 & 0.150 & -63.85 & 10.07 \\
\hline & Atrial fibrillation & 0.080 & -16.15 & 7.15 & 0.029 & -30.53 & -1.76 \\
\hline & Myocardial infarction & 0.086 & -27.09 & 11.62 & 0.024 & -50.48 & -3.70 \\
\hline & Ischemic heart disease & 0.055 & -14.44 & 7.45 & 0.059 & -29.45 & 0.57 \\
\hline & Heart failure & 0.027 & -11.37 & 7.49 & 0.136 & -26.45 & 3.70 \\
\hline & Coronary artery disease & 0.112 & -33.37 & 12.66 & 0.011 & -58.84 & -7.89 \\
\hline & Diabetes mellitus & -0.004 & -9.55 & 10.54 & 0.370 & -30.77 & 11.66 \\
\hline & Dyslipidemia & -0.20 & 2.38 & 7.95 & 0.766 & -13.628 & 18.39 \\
\hline \multirow[t]{4}{*}{ Circulation } & Anterior circulation & 0.026 & -11.82 & 7.91 & 0.142 & -27.74 & 4.10 \\
\hline & - Left hemisphere & -0.019 & -2.95 & 7.74 & 0.705 & -18.53 & 12.63 \\
\hline & - Right hemisphere & 0.003 & -8.60 & 8.00 & 0.288 & -24.70 & 7.50 \\
\hline & Posterior circulation & 0.026 & 11.82 & 7.91 & 0.142 & -4.10 & 27.74 \\
\hline \multirow[t]{2}{*}{ Stroke severity (NIHSS) } & $\begin{array}{l}\text { NIHSS on admission (each additional } \\
\text { point) }\end{array}$ & 0.436 & -3.73 & 0.61 & $<0.001$ & -4.96 & -2.50 \\
\hline & $\begin{array}{l}\text { NIHSS on discharge } \\
\text { (each additional point) }\end{array}$ & 0.733 & -5.36 & 0.47 & $<0.001$ & -6.31 & -4.42 \\
\hline \multirow{4}{*}{$\begin{array}{l}\text { Computed Tomogra- } \\
\text { phy }(\mathrm{CT}) \text { on admission }\end{array}$} & Visible acute ischemic stroke & -0.002 & -7.25 & 7.68 & 0.350 & -22.70 & 8.21 \\
\hline & Silent strokes & -0.18 & -3.27 & 7.49 & 0.665 & -18.35 & 11.81 \\
\hline & Hyperdence middle brain artery & 0.028 & -11.616 & 7.56 & 0.131 & -26.84 & 3.60 \\
\hline & ASPECTS (each additional point less) & -0.020 & -0.305 & 1.068 & 0.776 & -2.46 & 1.84 \\
\hline \multirow{4}{*}{$\begin{array}{l}\text { Computed Tomog- } \\
\text { raphy }(C T) 24 \text { h after } \\
\text { thrombolysis }\end{array}$} & Formed ischemic zone & 0.031 & -11.64 & 7.37 & 0.121 & -26.47 & 3.20 \\
\hline & Formed hemorrhagic zone & -0.008 & -12.22 & 15.40 & 0.432 & -43.22 & 18.79 \\
\hline & $\begin{array}{l}\text { Formed ischemic zone with hemor- } \\
\text { rhagic infarction }\end{array}$ & -0.001 & -13.03 & 13.44 & 0.337 & -40.09 & 14.03 \\
\hline & No dynamics & 0.144 & 18.82 & 7.09 & 0.011 & 4.55 & 33.09 \\
\hline \multirow[t]{4}{*}{ Door-to-needle time } & $<60$ min & 0.119 & 19.03 & 7.03 & 0.009 & 4.88 & 33.17 \\
\hline & $60-120 \mathrm{~min}$ & 0.016 & -10.07 & 7.61 & 0.192 & -25.39 & 5.25 \\
\hline & $>120 \min$ & 0.123 & -39.63 & 14.36 & 0.008 & -68.54 & -10.72 \\
\hline & For each additional minute & 0.153 & -0.39 & 0.13 & 0.004 & -0.64 & -0.13 \\
\hline
\end{tabular}

Bold values indicate $P$ value is significant (less than 0.05 )

NIHSS National Institutes of Health Stroke Scale, ASPECTS Alberta Stroke Programme Early CT Score

group were functionally dependant, but without significant intergroup difference with the NTP group. During the follow-up, these differences decreased, and in the third month, there were no disparities between the TP and NTP group. In previous studies in Bulgaria were reported significantly decreased rates of early mortality and severity of the neurological deficit after intravenous thrombolysis. The authors also reported that these results were not associated with a significant impact on the functional outcome on the third-month post-stroke in comparison with non-thrombolized patients [24]. The most constant predictor of poor clinical outcome and low HR-QoL was the severity of the ischemic stroke [25, 26]. We found a constant negative relation between the total NIHSS score, both at admission and discharge with the HR-QoL in the third-month post-thrombolysis. The higher NIHSS and mRS scores, and the lower HR-QoL measured by SIS 3.0 on discharged presented with high 
Table 4 Area under the curve (AUC) and significance values for the ROC curves measuring the discriminatory capacity of different variables on admission with the functional dependence on the third-month post-stroke

\begin{tabular}{|c|c|c|c|c|c|}
\hline \multirow[t]{2}{*}{ Variable } & \multirow[t]{2}{*}{ AUC } & \multirow[t]{2}{*}{ Std. Error } & \multirow[t]{2}{*}{ Significance } & \multicolumn{2}{|c|}{ 95\% Confidence interval } \\
\hline & & & & Lower Bound & Upper Bound \\
\hline Age & 0.611 & 0.050 & 0.036 & 0.514 & 0.708 \\
\hline CT on admission-Hyperdence MCA & 0.598 & 0.054 & 0.064 & 0.492 & 0.704 \\
\hline CT after $24 \mathrm{~h}$ —Visualized Ischemic zone & 0.528 & 0.054 & 0.596 & 0.423 & 0.633 \\
\hline CT after $24 \mathrm{~h}$ —Visualized Hemorrhagic zone & 0.502 & 0.053 & 0.975 & 0.398 & 0.605 \\
\hline NIHSS on admission & 0.854 & 0.031 & $<0.001$ & 0.793 & 0.916 \\
\hline NIHSS on discharge & 0.946 & 0.020 & $<0.001$ & 0.906 & 0.986 \\
\hline mRS on discharge & 0.982 & 0.008 & $<0.001$ & 0.966 & 0.999 \\
\hline SIS Total Quality of life on discharge & 0.965 & 0.015 & $<0.001$ & 0.937 & 0.994 \\
\hline
\end{tabular}

Bold values indicate $P$ value is significant (less than 0.05)

NIHSS National Institutes of Health Stroke Scale, mRS modified Rankin Scale, CT Computed Tomography, MCA Middle Cerebral Artery, SIS Stroke Impact

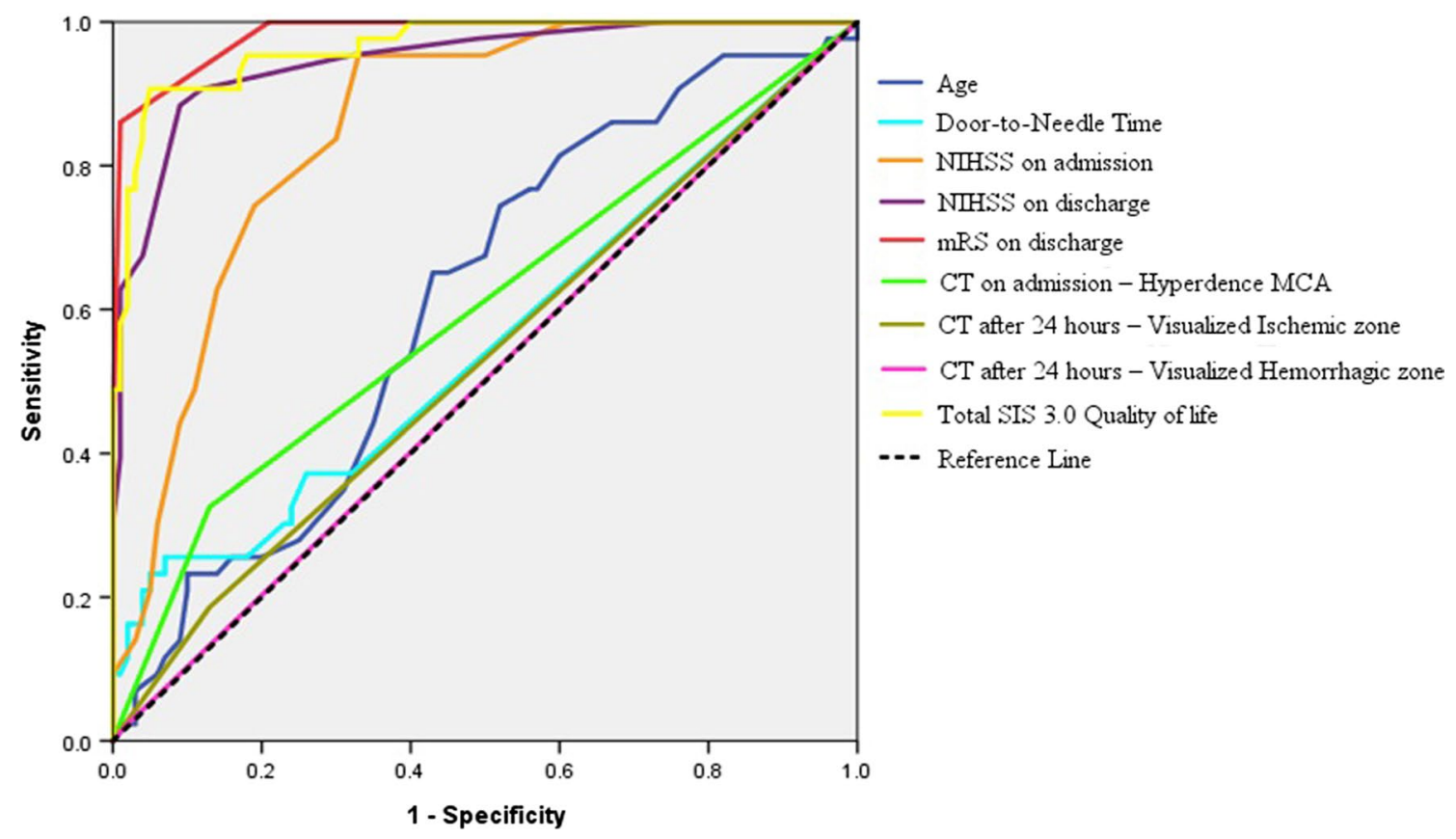

Fig. 1 Receiver operating characteristic (ROC) curves for functional dependency on the third-month post-stroke

specificity and sensitivity as predictors for a poor functional outcome on the third month. The two instruments NIHSS and mRS were also reported with good discriminating characteristics concerning the functional outcome 1 year after the AIS [27].

Door to needle (DTN) time provides valuable insight into stroke care workflow and is a performance indicator of an acute stroke unit [28]. The benefit of thrombolytic therapy is time-dependent, and previous studies have shown that shorter DTN time is associated with significantly better functional outcomes and fewer complications [29-31]. The results from our study are consistent with these from previous studies. DTN of 60 min or less was a predictive factor for favorable functional outcome and better HR-QoL. On the contrary, DTN of $60 \mathrm{~min}$ or more was significantly associated with poor clinical outcome. The analysis of the ROC curve revealed low discriminatory capacity in the current population. Nevertheless, in a previous study, including 58,353 patients treated with thrombolysis, the authors found that reducing the DTN time with 15 min results in a $4 \%$ better chance for walking independently at discharge [29]. We highlight the need for changes in the healthcare systems and education of stakeholders to reduce the 
DTN $<60$ min worldwide to achieve improvement in the HR-QoL after thrombolysis.

\section{Limitations}

We acknowledge the following limitations in our study. First, our cohort represents patients predominantly with minor and moderate stroke. Other aspects related to stroke outcomes such as psychoemotional disorders, family, and social support can also influence the HR-QoL and are not analyzed in the present study. Consequently, the results likely underestimate the full impact of stroke on the wellbeing of stroke-survivors.

Nevertheless, our results indicated the substantial impact of ischemic stroke on the self-reported Quality of life in our population. There is a lack of studies in our country about HR-QoL after ischemic stroke, especially for patients treated with intravenous thrombolysis. A more extensive prospective study might be of interest to address the Health-related Quality of life after thrombolysis in ischemic stroke-survivors in Bulgaria.

\section{Conclusions}

There are no significant differences in the primary HRQoL results and functional outcome in patients with intravenous thrombolysis and those without thrombolytic therapy within the first 3 months after stroke. Thrombolized patients had an initially higher neurological deficit on admission, but yet due to the differentiated treatment, they presented with an almost equal level of disability and Quality of life. Therefore, thrombolysis is a treatment option of great importance for improving the clinical outcomes after ischemic stroke.

The risk factors with predictive value for poor HR-QoL in thrombolized patients are atrial fibrillation, myocardial infarction, coronary artery disease, the higher NIHSS score and the longer, more than $60 \mathrm{~min}$, DTN time. The higher NIHSS and mRS scores and the lower HR-QoL measured by SIS 3.0 on discharge have high specificity and sensitivity as predictors for a poor functional outcome on the third month.

\footnotetext{
Abbreviations

ADL: Activities of daily living; AF: Atrial fibrillation; AIS: Acute ischemic stroke; AUC: Area under the curve; CAD: Coronary artery disease; CT: Computed tomography; HR-QoL: Health-related Quality of life; IVT: Intravenous thrombolysis; DTN: Door to needle time; SIS 3.0: Stroke Impact Scale Version 3.0; MI: Myocardial infarction; MRI: Magnetic resonance imaging; mRS: Modified Rankin Scale; NIHSS: National Institutes of Health Stroke Scale; TP: Thrombolized patients; NTP: Non-thrombolized patients; QoL: Quality of life; ROC: Receiver operator characteristic; SICH: Symptomatic intracerebral hemorrhage; TIA: Transient ischemic attack; TOAST: Trial of ORG 10172 in Acute Stroke Treatment.
}

\section{Acknowledgements}

None

\section{Authors' contributions}

MTM was a major contributor in the design of the article, literature research, collecting and interpreting the patient data regarding quality of life, and also was involved in the statistical analysis, data visualization and writing the manuscript. SA was a major contributor in the design of the article, literature research, and in writing the manuscript. All authors read and approved the final manuscript.

\section{Funding}

This research received no specific grant from any funding agency in the public, commercial, or not-for-profit sectors.

\section{Availability of data and materials}

The authors confirm that the data supporting the findings of this study are available within the article [and/or] its supplementary materials.

\section{Declarations}

Ethics approval and consent to participate

Ethical approval for this study was obtained from the Ethical commission at Medical University "Prof. Dr. Paraskev Stoyanov"Varna (Approval № 83/ 16.05.2019). All participants signed an informed consent prior their participation in the present study.

\section{Consent for publication}

The authors give their consent for the publication in the Journal.

\section{Competing interests}

The authors declare that there is no conflict of interest.

\section{Author details}

${ }^{1}$ Department of Neurology and Neuroscience, Faculty of Medicine, Medical University "Prof. Paraskev Stoyanov", Varna, Bulgaria. ${ }^{2}$ Second Clinic of Neurology With ICU and Stroke Unit, University Hospital "St. Marina", Varna, Bulgaria.

Received: 1 June 2021 Accepted: 19 November 2021

Published online: 05 December 2021

\section{References}

1. Donkor ES. Stroke in the 21(st) century: a snapshot of the burden, epidemiology, and quality of life. Stroke Res Treat. 2018;2018:3238165.

2. Labberton AS, Augestad LA, Thommessen B, Barra M. The association of stroke severity with health-related quality of life in survivors of acute cerebrovascular disease and their informal caregivers during the first year post stroke: a survey study. Qual Life Res. 2020. https://doi.org/10.1007/ s11136-020-02516-3.

3. Hacke W, Kaste M, Bluhmki E, Brozman M, Dávalos A, Guidetti D, et al. Thrombolysis with alteplase 3 to 4.5 hours after acute ischemic stroke. N Engl J Med. 2008;359(13):1317-29.

4. Lackland DT, Roccella EJ, Deutsch AF, Fornage M, George MG, Howard G, et al. Factors influencing the decline in stroke mortality: a statement from the American Heart Association/American Stroke Association. Stroke. 2014:45(1):315-53.

5. de Weerd L, Rutgers WA, Groenier KH, van der Meer K. Perceived wellbeing of patients one year post stroke in general practice-recommendations for quality aftercare. BMC Neurol. 2011;11:42.

6. Hankey GJ, Jamrozik K, Broadhurst RJ, Forbes S, Anderson CS. Long-term disability after first-ever stroke and related prognostic factors in the Perth Community Stroke Study, 1989-1990. Stroke. 2002;33(4):1034-40.

7. Berge E, Whiteley W, Audebert H, De Marchis GM, Fonseca AC, Padiglioni $C$, et al. European Stroke Organisation (ESO) guidelines on intravenous thrombolysis for acute ischaemic stroke. Eur Stroke J. 2021. https://doi. org/10.1177/2396987321989865.

8. Sacco RL, Kasner SE, Broderick JP, Caplan LR, Connors JJ, Culebras A, et al. An updated definition of stroke for the 21st century: a statement for healthcare professionals from the American Heart Association/American Stroke Association. Stroke. 2013;44(7):2064-89. 
9. Chung JW, Park SH, Kim N, Kim WJ, Park JH, Ko Y, et al. Trial of ORG 10172 in Acute Stroke Treatment (TOAST) classification and vascular territory of ischemic stroke lesions diagnosed by diffusion-weighted imaging. JAHA. 2014. https://doi.org/10.1161/JAHA.114.001119.

10. Brott T, Adams HP Jr, Olinger CP, Marler JR, Barsan WG, Biller J, et al. Measurements of acute cerebral infarction: a clinical examination scale. Stroke. 1989;20(7):864-70.

11. Broderick JP, Adeoye $O$, Elm J. Evolution of the modified rankin scale and its use in future stroke trials. Stroke. 2017;48(7):2007-12.

12. Duncan P, Bode R, Lai S, Perera S. Rasch analysis of a new stroke-specific outcome scale: the Stroke Impact Scale. Arch Phys Med Rehabil. 2003;84:950-63.

13. Lai SM, Studenski S, Duncan PW, Perera S. Persisting consequences of stroke measured by the Stroke Impact Scale. Stroke. 2002;33(7):1840-4.

14. Tsalta-Mladenov M, Georgieva D, Andonova S. Measuring Quality of Life in Stroke Survivors. Russian Neurol J. 2020;25(3):11-6.

15 Hosmer DW Jr, Lemeshow S, Sturdivant RX. Applied logistic regression. New York: John Wiley \& Sons; 2013.

16. Tsalta-Mladenov M, Dimitrova V, Georgieva-Hristova D, Andonova S. Study on the risk profile of patients with acute stroke hospitalized in the Second Clinic of Neurology, St Marina University Hospital. Varna Medical Forum. 2019;8(1):73-8.

17. Asdaghi N, Wang K, Ciliberti-Vargas MA, Gutierrez CM, Koch S, Gardener $\mathrm{H}$, et al. Predictors of thrombolysis administration in mild stroke: Florida-Puerto Rico collaboration to reduce stroke disparities. Stroke. 2018;49(3):638-45.

18. Marto JP, Kauppila LA, Jorge C, Calado S, Viana-Baptista M, Pinho-e-Melo $T$, et al. Intravenous thrombolysis for acute ischemic stroke after recent myocardial infarction. Stroke. 2019;50(10):2813-8.

19. PalomerasSoler E, Casado RV. Epidemiology and risk factors of cerebral ischemia and ischemic heart diseases: similarities and differences. Curr Cardiol Rev. 2010;6(3):138-49.

20. Sung SF, Chen YW, Tseng MC, Ong CT, Lin HJ. Atrial fibrillation predicts good functional outcome following intravenous tissue plasminogen activator in patients with severe stroke. Clin Neurol Neurosurg. 2013;115(7):892-5.

21. Saposnik G, Gladstone D, Raptis R, Zhou L, Hart RG. Atrial fibrillation in ischemic stroke: predicting response to thrombolysis and clinical outcomes. Stroke. 2013;44(1):99-104.

22. Tu HT, Campbell BC, Christensen S, Desmond PM, De Silva DA, Parsons $M W$, et al. Worse stroke outcome in atrial fibrillation is explained by more severe hypoperfusion, infarct growth, and hemorrhagic transformation. Int J Stroke. 2015;10(4):534-40.

23 Yue R, Li D, Yu J, Li S, Ma Y, Huang S, et al. Atrial fibrillation is associated with poor outcomes in thrombolyzed patients with acute ischemic stroke: a systematic review and meta-analysis. Medicine. 2016. https://doi. org/10.1097/MD.0000000000003054.

24. Андонова С, Георгиева Д, Калевска Е, Аргирова В, Димитрова В Оценка на факторите, повлияващи изхода от остър исхемичен мозъчен инсулт. Известия на съюза на учените. 2015;1:28-34.

25. Ramos-Lima MJM, Brasileiro IC, Lima TL, Braga-Neto P. Quality of life after stroke: impact of clinical and sociodemographic factors. Clinics (Sao Paulo). 2018;73:e418.

26. Guidetti S, Ytterberg C, Ekstam L, Johansson U, Eriksson G. Changes in the impact of stroke between 3 and 12 months post-stroke, assessed with the Stroke Impact Scale. J Rehabil Med. 2014;46(10):963-8.

27. Mar J, Masjuan J, Oliva-Moreno J, Gonzalez-Rojas N, Becerra V, Casado MÁ et al. Outcomes measured by mortality rates, quality of life and degree of autonomy in the first year in stroke units in Spain. Health Qual Life Outcomes. 2015;13(1):36.

28. Raina A, Trivedi M, Kate M, Kumar L, EratSreedharan S, Sylaja PN. Temporal sustainability of guideline based door-to-needle times for intravenous thrombolysis for acute ischemic stroke. J Clin Neurosci. 2020;74:164-7.

29. Saver JL, Fonarow GC, Smith EE, Reeves MJ, Grau-Sepulveda MV, Pan W, et al. Time to treatment with intravenous tissue plasminogen activator and outcome from acute ischemic stroke. JAMA. 2013:309(23):2480-8.

30. Harvey J, Al Kasab S, Almallouhi E, Guerrero WR, Debenham E, Turner $\mathrm{N}$, et al. Door to needle time and functional outcome for mild ischemic stroke over telestroke. J Telemed Telecare. 2019;25(6):365-9.

31. Emberson J, Lees KR, Lyden P, Blackwell L, Albers G, Bluhmki E, et al. Effect of treatment delay, age, and stroke severity on the effects of intravenous thrombolysis with alteplase for acute ischaemic stroke: a meta-analysis of individual patient data from randomised trials. Lancet. 2014;384(9958):1929-35.

\section{Publisher's Note}

Springer Nature remains neutral with regard to jurisdictional claims in published maps and institutional affiliations.

\section{Submit your manuscript to a SpringerOpen ${ }^{\circ}$ journal and benefit from:}

- Convenient online submission

- Rigorous peer review

- Open access: articles freely available online

- High visibility within the field

- Retaining the copyright to your article

Submit your next manuscript at $\boldsymbol{\nabla}$ springeropen.com 